Computational Study of 3-D Hot-Spot Initiation in Shocked Insensitive High-Explosive

F. Najjar, W. Howard, L. Fried, M. Manaa, A. Nichols III, G. Levesque

July 20, 2011

17th Biennial International Conference of the APS Topical Group on Shock Compression of Condensed Matter Chicago, IL, United States June 26, 2011 through July 1, 2011 
This document was prepared as an account of work sponsored by an agency of the United States government. Neither the United States government nor Lawrence Livermore National Security, LLC, nor any of their employees makes any warranty, expressed or implied, or assumes any legal liability or responsibility for the accuracy, completeness, or usefulness of any information, apparatus, product, or process disclosed, or represents that its use would not infringe privately owned rights. Reference herein to any specific commercial product, process, or service by trade name, trademark, manufacturer, or otherwise does not necessarily constitute or imply its endorsement, recommendation, or favoring by the United States government or Lawrence Livermore National Security, LLC. The views and opinions of authors expressed herein do not necessarily state or reflect those of the United States government or Lawrence Livermore National Security, LLC, and shall not be used for advertising or product endorsement purposes. 


\title{
COMPUTATIONAL STUDY OF 3-D HOT-SPOT INITIATION IN SHOCKED INSENSITIVE HIGH-EXPLOSIVE
}

\author{
F.M. Najjar ${ }^{1}$, W.M. Howard ${ }^{2}$, L.E. Fried ${ }^{2}$, \\ M.R. Manaa ${ }^{2}$, A. Nichols III ${ }^{2}$, and G. Levesque ${ }^{2}$ \\ ${ }^{1}$ B-Division, Lawrence Livermore National Laboratory, 7000 East Avenue, L-95, Livermore CA 94551 \\ ${ }^{2}$ CMELS Division, Lawrence Livermore National Laboratory, 7000 East Avenue, Livermore CA 94551
}

\begin{abstract}
High-explosive (HE) material consists of large-sized grains with micron-sized embedded impurities and pores. Under various mechanical/thermal insults, these pores collapse generating hightemperature regions leading to ignition. A hydrodynamic study has been performed to investigate the mechanisms of pore collapse and hot spot initiation in TATB crystals, employing a multiphysics code ALE3D coupled to the chemistry module, Cheetah. This computational study includes reactive dynamics. Two-dimensional high-resolution large-scale meso-scale simulations have been performed The parameter space is systematically studied by considering various shock strengths, pore diameters and multiple pore configurations. Preliminary 3-D simulations are undertaken to quantify the threedimensionality dynamics. LLNL-PROC-XXXXX
\end{abstract}

Keywords: Hydrodynamics, reactive flow, shocked TATB, pore collapse, Cheetah, ALE3D.

PACS: 44.35.+c, 62.50.Ef, 95.30.Lz.

\section{INTRODUCTION}

Solid plastic-bonded high-explosive (HE) materials consist of crystals that are usually between 10 and 100 microns, with micron-sized impurities and pores embedded inside the crystals. These voids increase the ease of shock initiation by generating high-temperature regions during their collapse that might lead to ignition. Understanding the mechanisms of hot-spot initiation in HE materials has had significant research interest in the literature due to safety, reliability and development of new insensitive munitions. Bowden \& Yoffe [1] systematically studied the role of void collapse. The main mechanisms of hot spot formation identified consist of adiabatic compression of small entrapped bubbles of gas, friction due to confining surfaces or extraneous grit particles, and intercrystalline friction of the explosive particles, and viscous heating of rapidly flowing explosive material. Frey [2] reviewed the theoretical effects concerning the role of voids in explosive initiation and ignition. Mader [3] studied numerically the shock initiation of detonation in nitromethane, liquid TNT and single-crystal PETN. Lee \& Tarver [4] proposed a phenomenological model for ignition and growth to compute shock initiation of heterogeneous HE materials. They compared their results of pressure and particle velocity gauges to experimental measurements of various $\mathrm{HE}$ materials.

The objectives of the current study are to investigate using the multiphysics computational framework, ALE3D, the mechanisms of pore collapse and hot spot initiation in simulated TATB crystals. TATB explosives are known their resistance to such external insults, referred to as HE "insensitivity". Our ultimate goal is to construct a multiscale computational framework focusing on initiation in IHE and provide a firstprinciple based model to improve deflagration models at mm-scale. 


\section{COMPUTATIONAL APPROACH}

The multiphysics software, ALE3D [5], is used to perform these simulations and consists of several physics modules, including hydrodynamics and thermal transport. The mathematical formulation is based on an Operator-Split method and invokes an arbitrary Lagrangian-Eulerian (ALE) approach in 3-D/2-D configuration. The thermo-chemistry solver, Cheetah [7], is tightly coupled to ALE3D and properly models appropriate kinetic reaction mechanisms, obtained from MD computations.

The current configuration is represented by a continuum material of an insensitive HE material, TATB, where an embedded defect consisting of a spherical air-filled pore is present with an initial diameter, $d_{p}$. The cylindrical computational domain consists of a rectangular grid with length and radius, $\mathrm{L}=54 \mu \mathrm{m}$, and $\mathrm{R}=16 \mu \mathrm{m}$, respectively. The dynamics of pore collapse have been verified to be independent of the computational length and radius ( $\mathrm{L}$ and $\mathrm{R}$ ) used. The following boundary conditions are imposed: a solid wall on the left boundary, and non-reflective outflow condition on the right boundary, with symmetric conditions on the top and bottom boundaries. Reverse ballistics are imposed initially where a uniform $\mathrm{x}$-velocity is set. Atmospheric conditions are chosen for the pressure field and temperature $(\mathrm{p}=1 \mathrm{~atm}$ and $\mathrm{T}=298 \mathrm{~K})$. Fig. 1 provides a schematic of the computational domain used for the current simulations.

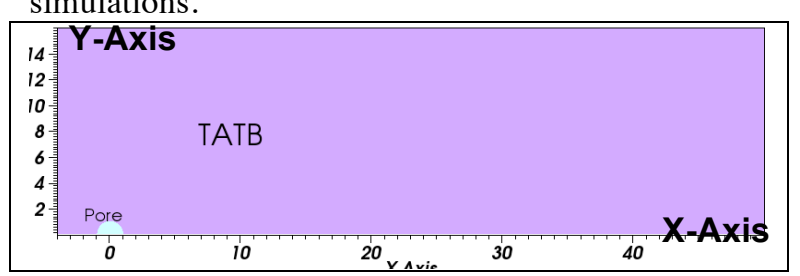

FIGURE 1. Schematic of computational domain, showing the pore embedded in an IHE. A large streamwise length is chosen to evolve the pore dynamics for over 10ns.

The chemical reactions for TATB are obtained from MD simulations where a 4-step approach was identified, making TATB into products; while the constitutive relation for air follows a Quotidian EOS (QEOS) [6]. Hence, the current hydrosimulations consist of a three-way coupled formalism, including the hydrodynamics and thermal transport modules in ALE3D, and
TABLE 1. Summary of TATB and Air properties at Standard Conditions

\begin{tabular}{lcc}
\hline \multicolumn{1}{c}{ Properties } & TATB & Air \\
\hline $\begin{array}{l}\text { Density }\left(\mathrm{g} / \mathrm{cm}^{3}\right) \\
\text { Heat Capacity }(\mathrm{J} / \mathrm{K}-\mathrm{kg})\end{array}$ & 1.90 & $1.129 \times 10^{-3}$ \\
Thermal Conductivity $(\mathrm{W} / \mathrm{m} / \mathrm{K})$ & 0.837 & 1.04 \\
Yield Strength $(\mathrm{Kbar})$ & 1.0 & 0.08 \\
Shear Modulus $(\mathrm{GPa})$ & 7 & - \\
Melt Temperature $(\mathrm{K})$ & 623 & 8.76 \\
Ignition Temperature $(\mathrm{K})$ & $\sim 2500$ \\
\hline
\end{tabular}

\section{RESULTS AND DISCUSSION}

Fig. 2 presents contours of temperature field at a representative time instance. The shock moves from the left direction (negative/small $\mathrm{x}$ ) to the right one (positive/large $\mathrm{x}$ ); while the pore is centered at the origin. As the shock propagates through the IHE material, HE melting occurs due to the thermal heating on the back side of the shock. Once the primary shock impinges on the pore, a primary jet (PJ) is generated in the softened HE material upstream of the shock (see Fig. 1a). That primary jet pushes on the front wall of the pore, moving it towards the back wall. Once the front wall merges with the back wall, the pore collapses and lifts from the centerline, becoming a torus. Several key features are identified in Fig. 2 including the primary shock, a heated IHE region caused by the pore collapse, a mach stem and the collapse pore. It is seen that the region around the collapsed pore has a significantly higher temperature compared to the primary shock. Further details will be discussed in [8]. The 
maximum temperature that is mass-averaged over all the products from the reaction was also computed and its time distribution shows a peak of $3500 \mathrm{~K}$ around $1 \mathrm{~ns}$ (time close to the pore collapse) before reaching a plateau value of $2100 \mathrm{~K}$. These typical values are relevant to the conditions for a $4 \mu \mathrm{m}$ pore diameter with an 36-GPa shock strength.

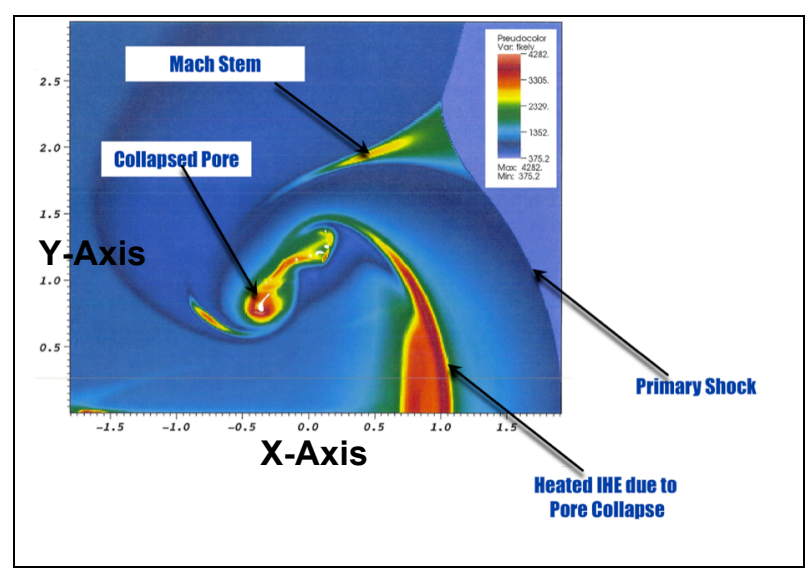

Figure 2. Contours of instantaneous temperature field for a spherical pore with a $4 \mu \mathrm{m}$ diameter and for a shock strength of $46 \mathrm{GPa}$. Contour levels extend in the range of [375K, 4282K].

Fig. 3 presents contours of the instantaneous reaction rate as the chemical reaction evolves in time in the vicinity of the pore collapse. Results are plotted from several shock strengths, showing the increase in reaction rate with increasing shock strength. The reaction zone propagates farther downstream at higher shock pressures. The last contour in each plot corresponds to a time instance of 10ns. Similar results for the reaction rate region are shown in Fig. 4 where two separate pore diameters are compared. It is seen that the reaction rate slows down with larger pore diameters. Hence, less reaction occurs as the pore diameter increases. There seems to be a critical pore diameter where the reaction rate is enhanced.

Preliminary 3-D computations were performed using a mesh resolution of $33.6 \mathrm{M}$ cells, corresponding to $40 \mathrm{cells} / \mu \mathrm{m}$. The pore diameter is $1 \mu \mathrm{m}$ while the shock strength is $25 \mathrm{GPa}$. Fig. 5(a) highlights the 3-D computational domain. Due to the computational requirements of 8192 processors, the domain size was substantially reduced over the $2 \mathrm{D}$ case discussed previously.

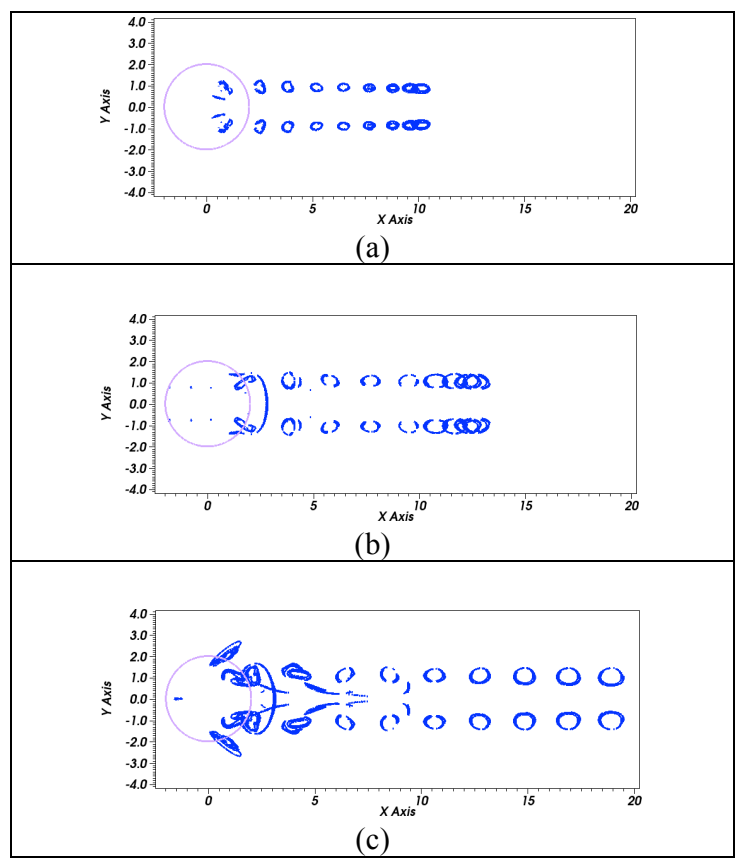

Figure 3. Time distribution of reaction rate level for an $4 \mu \mathrm{m}$ pore diameter with several shock strengths of: (a) $10 \mathrm{GPa}$, (b) $25 \mathrm{GPa}$, and (c) $36 \mathrm{GPa}$. Also shown in purple contour the initial pore diameter.

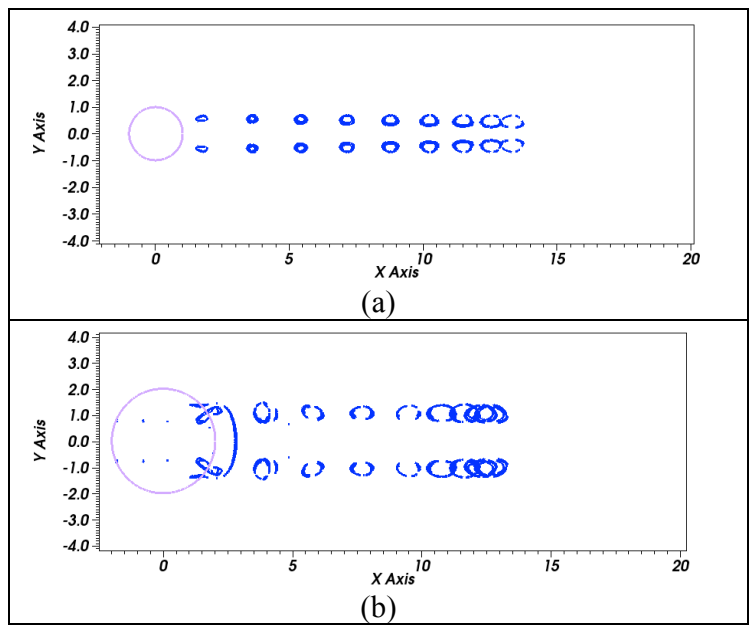

Figure 4. Reaction rate level with a 25-GPa shock strength and for diameters of: (a) $2 \mu \mathrm{m}$, and (b) $4 \mu \mathrm{m}$. Also shown in purple contour the initial pore diameter.

Fig. 5(b) plots the instantaneous reaction front, capturing three-dimensionality in its evolution. However, the mesh resolution is, at best, marginal 
and substantial increase in the mesh size is required to further quantify such effects.

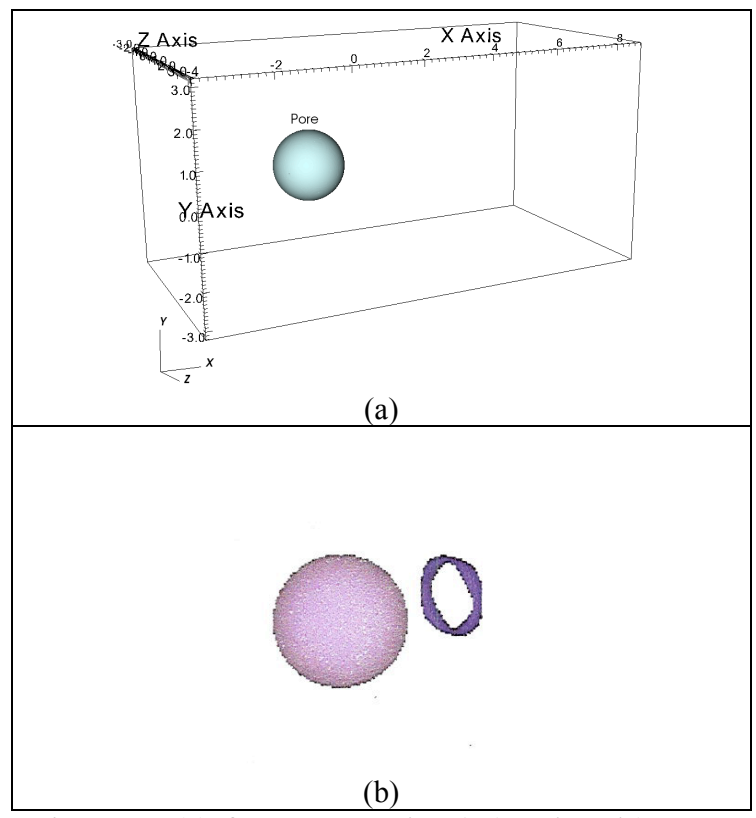

Figure 5. (a) 3-D computational domain with a pore diameter of $1 \mu \mathrm{m}$, (b) 3-D contours of the instantanesous reaction rate. Also shown in purple contour the initial spherical pore.

Finally, contours of the temperature field in the TATB material are shown in Fig. 4 as obtained for two pore radii of 1 and $2 \mu \mathrm{m}$. The coupled Hydrodynamic-Thermal analysis is used. The hot spot temperature is observed to increase with larger pore radius, highlighting that the thermal transport mechanism is not scale invariant, as opposed to the hydrodynamic phenomena.

\section{CONCLUSIONS}

Two-dimensional high-resolution meso-scale simulations have been performed on an axisymmetric pore configuration in a shocked TATB material using the multiphysics software, ALE3D. ALE3D[5] is a massively parallel hydrodynamics framework and coupling of the hydrodynamics with the thermal transport has been used. A three-way coupling process is invoked, including chemistry using Cheetah[7]. A refined four-step reactive model obtained from Ab-initio MD computations has been applied. Results have been described for various pore sizes and different shock pressures. It is seen that the temperature field of the IHE mass-averaged over all the products has a peak value of $3500 \mathrm{~K}$, before settling at a plateau of $\sim 200 \mathrm{~K}$. The reaction fronts are tracked in time, showing enhancements due to shock strength and slowdown due to increase pore size. 3-D preliminary computations were performed and highlight growth of three-dimensionality in the reaction field. Future work will focus on higher mesh resolution in $3 \mathrm{D}$ and accounting for viscous effects.

\section{ACKNOWLEDGEMENTS}

This work was performed under the auspices of the U.S. Department of Energy by Lawrence Livermore National Security under contract No. DE-AC52-07NA27344. The authors acknowledge the numerous discussions with C. Tarver, R. McCallen, N. Barton and J. Banks.

\section{REFERENCES}

1. Bowden, F.P., \& Yoffe, A.D., Initiation and Growth of Explosions in Liquids and Solids, Cambridge Univ. Press, New York, 1951.

2. Frey, R.B., "Cavity Collapse in Energetic Materials," Proceedings-Eighth Symposium on Detonation, 385-393, 1985.

3. Mader, C., "Shock and Hot Spot Initiation of Homogeneous Explosives," Phys. Fluids, 6(3): 375381, 1963.

4. Lee, E.L., \& Tarver, C.M., "Phenomenological Model of Shock Initiation in Heterogeneous Explosives,' Phys. Fluids, 23(12): 2362-2372, 1980.

5. Nichols, A.L. et al., "ALE-3D User's Manual", LLNL Technical Report, UCRL-MA-152204, 2007.

6. More, R.M., et al., "New Quotidian Equation of State (QEOS) for Hot Dense Matter", Phys Fluids, 31(10):3059-3078, 1988.

7. Fried, L.E., \& Howard, M.W., "An Accurate Equation of State for the Exponential-6 Fluid Applied to Dense Supercritical Nitrogen," J. Chem. Physics, 109(10):7338-7349, 1998.

8. Najjar, F.M., Howard, M.W., and Fried, L.E., "Meso-scale Simulations of Hot-Spot Initiation in Shocked Insensitive Explosives," to be submitted to J. Appl. Physics, 2011. 